\title{
Corporeidad y motricidad. Una forma de mirar los saberes del cuerpo
}

Corpority and motor function: a way to look at the knowledges of body

Deibar René Hurtado Herrera

Resumen

Corporeidad y motricidad no son simples distinciones utilizadas para refinar el lenguaje, son dos conceptos de tradición fenomenológica que han empezado a ser utilizados en los últimos tiempos en el contexto de una nueva "ciencia" llamada Motricidad Humana. La problematización de algunos supuestos tiene la pretensión de aportar en la configuración de conocimiento situado, un entramado epistémico que, en lugar de cortar y excluir, seduzca y convoque; al fin y al cabo toda apuesta de ordenamiento llamada conocimiento será siempre una forma de mirar los saberes inabarcables del cuerpo.

Palabras clave: Motricidad, corporeidad, máquinas ópticas, significaciones imaginarias.

\section{Abstract}

Corpority and motor function are not simple distinctions used to refine language. They are two concepts from a phenomenological tradition, that have recently started to be used within the context of a new "science" called human motor function. The problematization of some assumptions is an attempt to make a contribution to the building of situated knowledge. An epistemic framework which, rather than cutting and excluding, seduces and convokes. Ultimately, every ordering attempt called knowledge will basically always be a way of looking at the incommensurate body knowledges.

Key words: $\quad$ Corpority, motor function, optical machine, imaginary meanings.

Fecha de recepción: 5 de octubre de 2007

Fecha de aceptación: 10 de noviembre de 2007.

\footnotetext{
* Licenciado en Educación Física. Candidato a doctor en Ciencias Sociales, Niñez y Juventud de la Universidad de Caldas-CINDE. Profesor de la Universidad del Cauca. Autor del libro Imaginarios de la Educación Física en la juventud de Popayán. deibarh@ unicauca.edu.co
} 


\section{Corporeidad, una aproximación necesaria}

La formación de licenciados en Educación Física y Deportes centró por mucho tiempo su reflexión en torno al cuerpo bio-fisiológico; sus referentes conceptuales estaban orientados a obtener mejores rendimientos a nivel deportivo, o a garantizar las condiciones para que estos rendimientos se dieran. Así como las prácticas pedagógicas en la educación física, se centraban en la técnica, el aprendizaje motor, la teoría del entrenamiento y el desarrollo de las capacidades físico-motrices. Pero cuando planteamos una educación física que contribuye en la formación humana, debemos detenernos a pensar cuáles son las implicaciones que tiene en cuanto a los referentes conceptuales una tarea de este tipo.

El cuerpo como realidad bio-fisiológica se constituye en un elemento importante a considerar, pero no es referente suficiente para comprender al ser humano. $\mathrm{El}$ cuerpo que se construye socialmente, que sufre un proceso de humanización a través de la educación, es el cuerpo de la educación física, y es, en este sentido, donde aparece el concepto de corporeidad como un concepto fundante para la educación física.

El concepto de corporeidad nos hace volver sobre la tríada cuerpo-sujeto-cultura o sobre lo que Morin (2001) denomina la relación bio-antropo-cultural. Esta relación no es otra cosa que el reconocimiento de la condición humana. En términos de Savater (1996), no es suficiente nacer para la humanidad, nos hacemos humanos con los demás y estos procesos de mediación cultural nos ubican dentro de la condición humana. La corporeidad es un concepto que se inscribe en la condición humana en la medida que reconoce el determinismo biológico de orden filogenético, pero lo trasciende y relaciona con los procesos de interacción social y de mediación cultural de orden ontogenético.

Para el propósito de este texto, es muy iluminador el concepto fenomenológico ${ }^{1}$ de corporeidad propuesto por Mèlich (1995: 79) en donde "ser corpóreo (leib-Sein) significa abrirse a toda una serie de dimensiones antropológicas y sociales. Significa ser-sí-mismo, pero también ser-tú, ser-con y ser-en-el-mundo. Pero no ser-enel mundo receptivo, paciente, sino básicamente activo, agente, ser-con-el-mundo (Mitderweltsein)". Es evidente

1 La fenomenología asumida a partir de Heidegger (2004: 45) [Primera edición en alemán, 1927], como ciencia de los fenómenos que permite ver lo que se muestra, tal como se muestra por sí mismo, efectivamente por sí mismo. O como es asumida por Merleau-Ponty (2000) [Primera edición en francés, 1945]. en el concepto propuesto la influencia de Heidegger para quien "ser-en" es la condición existenciaria ${ }^{2}$ del "ser ahî", por tanto, la evidencia de que el "ser ahí" existe.

Ser "en" implica entonces "habitar en", "detenerse en", "estar habituado", "familiarizado", "frecuentado", por tanto, habito el mundo como algo que me es familiar. De ahí que ser-en-el mundo y ser-con-el mundo son expresiones de un cuerpo-sujeto que configura su subjetividad en la intersubjetividad, lo que implica, la combinación de un ser situado (Befindlichkeit) con un ser sintonizado (stimmung). Entonces, mi cuerpo como corporeidad desde la cual soy en el mundo y desde la cual accedo al mundo está inmersa en el mundo, en un entramado de significaciones imaginarias que determina mi horizonte de sentido y que está en sintonía con mi inmersión en el mundo ${ }^{3}$.

Esta claridad en relación a cómo mi ser-en-el mundo es inmersión y sintonía de mi ser corpóreo en el mundo, se hace necesaria debido a que implica asumir en perspectiva crítica la propuesta de Merleau-Ponty (2000) de una fenomenología de la percepción. Si soy mi cuerpo y a través de él estoy en el mundo y si el mundo es aquello que percibo, estaría dejando por fuera esa familiaridad y esa habituación de mi ser-en-el-mundo, aquellas formas particulares de percibir y de ver el mundo que me han sido compartidas al ser-con-otros. Por estar en el mundo estamos condenados al sentido diría MerleauPonty, pero es, precisamente, ese sentido en la intersección de mis experiencias con las del otro (subjetividad e intersubjetividad).

Sin embargo, al plantear que la corporeidad también implica ser-con-el-mundo de manera activa, implica que puedo re-significar el mundo y su significaciones, los entramados de sentido que configuro en procesos poéticos que son capaces trasformar el ser-sí-mismo y el ser-tú, y que pueden partir de acciones sobre el sí mismo que afectan la relación con los otros y con el mundo ${ }^{4}$.

Esta inmersión en el mundo que no es posible sino a través de nuestro cuerpo, que es la mediación fundamental desde la cual se introyecta el orden social, ideologías, valores, formas de subjetividad; a este proceso

\footnotetext{
2 La pregunta por las estructuras complejas que constituyen la existencia no tienen un carácter existencial sino existenciario (Heidegger, 2004: 22).

3 Se asume mundo en la perspectiva de Heidegger en le cual éste puede comprenderse "como aquello 'en que' un 'ser ahí fáctico, en cuanto este 'ser ahi' 'vive.' Mundo tiene una significación preontológicamente existencial. Aquí vuelve a hacer diversas posibilidades: 'mundo' mienta el mundo 'público' del 'nosotros' o el mundo circundante 'peculiar' y más cercano (doméstico)" (2004: 78)

4 Para ampliar, en Foucault (1984) [primera edición en francés, 1975].
} 
McLaren le denomina encarnación: "ser encarnado no es solo apropiarse de símbolos, sino, también, identificarse con el símbolo del que uno se apropia, es decir, consiste en identificarse uno mismo con el propio símbolo y, también, alcanzar una correspondencia entre la posición del sujeto proporcionado por el discurso y el sujeto" (McLaren, 1997: 90).

Corporeidad y encarnación son conceptos que reconocen los procesos mediante los cuales la cultura se inscribe en el cuerpo y nos permiten encontrar en él un espacio de convergencia discursiva, un lugar de intervención. El cuerpo, entonces, ha sido intervenido y los discursos que encarna han sido construidos con propósitos definidos socialmente, de tal manera que el valor social del cuerpo depende del propósito con que se interviene. Si asumimos que la "cultura no puede pensarse despegada de los procesos materiales de producción" (Rodríguez, 1997: 4), comprenderemos las razones por las cuales en la modernidad se hacía necesario la formación de un cuerpo productivo, por lo tanto fuerte y saludable, pero que al mismo tiempo fuera dócil, obediente y disciplinado 5 .

En perspectiva fenomenológica, la corporeidad es el concepto clave desde el que se ha construido esa forma de ordenamiento del conocimiento denominada Motricidad Humana. Es una salida desde la cual se ha pretendido visibilizar la multidimensionalidad del ser humano como ser corpóreo. Para el equipo Kon-traste la corporeidad se asume como proyecto de humanización a través de la acción, como vivenciación del hacer, sentir, pensar y querer, que reconoce en su condición de humano la incorporación de todo su yo; "el yo implica el hacer, el saber, el pensar, el comunicar y el querer" y es "condición de presencia, participación y significación del hombre en el mundo" (Trigo et ál. 1999: 60).

Subiste igualmente la pregunta si existe corporeidad o corporeidades, al fin y al cabo, pueden existir tantas formas de estar en-el mundo y de ser-con-el-mundo, tantas formas de "ser-sí-mismo" y de "ser-con" que podrían existir muchas corporeidades en un solo ser humano y tantas corporeidades como seres humanos existen.

\section{Acerca del concepto de motricidad}

Creo que no es desconocido el aporte de Merleau-Ponty en la posterior tesis doctoral que realizó Manuel Sergio y que dio paso a lo que hoy se conoce como la Ciencia de la Motricidad Humana, sin embargo, creo no está claro

\footnotetext{
5 Para ampliar, en Foucault (1984).
}

todavía que el concepto de Motricidad fue retomado por Merleau-Ponty (2000) de Grünbaum en donde:

La motricidad en estado puro, ya posee el poder elemental de dar sentido (Sinngebung). Aún cuando, más adelante, el pensamiento y la percepción del espacio se liberen de la motricidad y del ser en el espacio, para que podamos representarnos el espacio es preciso que hayamos, primero, sido introducidos en él por nuestro cuerpo y que éste nos haya dado el primer modelo de transposiciones, de las equivalencias, de las identificaciones, que hacen del espacio un sistema objetivo y permiten a nuestra experiencia ser una experiencia de objetos, de abrirse a un "en sí". La motricidad es la esfera primaria en donde se engendra, primero, el sentido de todas las significaciones (der Sinn aller signifikationen) en el dominio del espacio representado (Merleau-Ponty, 2000: 159).

La intención al traer la cita que de Grünbaum hace Merleau-Ponty es mostrar que todo gesto humano tiene una significación, pero queda claro que cuando éste se refiere a la "motricidad en estado puro", a la posibilidad de "liberar el pensamiento" y "la percepción del espacio de la motricidad", que era a lo que hacia alusión en cuanto al movimiento de un cuerpo que está en-el-mundo, movimiento como esfera primaria en donde se engendra el significado. No se puede desconocer que fueron muchos planteamientos que Manuel Sergio (1999) retomó de Merleau-Ponty, entre ellos: la comprensión de la fenomenología como una ciencia de la existencia, pero de una existencia encarnada en un mundo vivido. Igualmente, la crítica a los dualismos cuerpo/alma y la comprensión del cuerpo-sujeto como red de intencionalidad ${ }^{6}$, como horizonte de posibilidades y fuente de

6 El concepto desde el cual se fundamenta esa intencionalidad es el de "arco intencional" retomado de Fischer por Merleau-Ponty (2000: 153) para quien "la vida de la consciencia - vida cognoscente, vida del deseo o vida perceptiva- viene subtendida por un "arco intencional" que proyecta, alrededor nuestro, nuestro pasado, nuestro futuro, nuestro medio contextual humano, nuestra situación física, nuestra situación ideológica, nuestra situación moral o, mejor, lo que hace que estemos situados bajo todas esas relaciones. En ese arco intencional lo que forma la unidad de sentidos, la de los sentidos y la inteligencia, la de la sensibilidad y la motricidad". La intencionalidad fenomenológica es cuestionada por diversos autores, como una de las principales dificultades que tiene Merleau-Ponty para superar el dualismo debido a que éste "presenta el pensamiento como si fuera una relación interiorizada, la consciencia y su objeto, la ideación y lo ideado, el polo noético y el polo noemático, o en la versión sartreana, el para-sí y el en-sí. Ahora, bien, como el pensamiento es precisamente el despliegue del Ser-uno, su condición nunca puede ser la relación interiorizada, la representación o la conciencia-de. El pensamiento supone que las modalidades de Ser son exteriores unas en relación a otras, que ninguna puede tener privilegio (como pretende tenerlo la conciencia) de interiorizar a las demás. (Deleuze citado por Badiou, 2005). Lo que implica que hay un algo y la consciencia de ese algo, hay un dos. (García, 2005: 57) En este mismo 
comunicación con el mundo, en donde el esquema corporal es espacialidad de situación y la subjetividad se construye por el cuerpo.

Manuel Sergio (1999) en su tesis doctoral ${ }^{7}$ propone un concepto de motricidad en el que ésta "es la base para la determinación del hombre. Es por ella que el hombre se materializa y revela, en el ámbito de un proceso donde el deseo de trascendencia desempeña un papel primordial de mediación", una forma concreta de relación del ser humano consigo mismo, con el mundo y con sus semejantes, una relación que se da a través de nuestra corporeidad, de la acción humana, caracterizada por la intencionalidad y por el significado.

La motricidad se configura, parafraseando a Kolyniak (2005: 29-37), como proceso, cuya constitución envuelve la construcción del movimiento intencional desde la reflexión y la creación de nuevas formas de interacción a partir de la reproducción de patrones aprendidos, de la acción contextualizada en la historia, por tanto, relacionada al pasado vivido y al futuro proyectado; expresando y construyendo la totalidad de las múltiples y complejas determinaciones de la continua construcción de lo humano.

Estos dos conceptos de motricidad humana son una clara evidencia de la forma como el concepto inicial de motricidad de Fischer fue nutrido por Manuel Sergio (1999) con los aportes del mismo Merleau-Ponty que lo había retomado y de otros autores que desde la fenomenología y desde la teoría de la complejidad, entre otras, fueron nutriendo la postura asumida por lo que se ha denominado una nueva ciencia ${ }^{8}$. La propuesta de hacer de la motricidad una ciencia es de Manuel Sergio, en ningún enunciado de lo propuesto por Merleau-Ponty (2000) en la Fenomenología de la percepción existe pretensión alguna en este sentido, y a pesar de compartir el 80 espíritu que ha inspirado todo este proceso de construcción hay elementos que valdría la pena considerar.

sentido podríamos ubicar la crítica de Zuleta (1980) al arco intencional afirmando que éste es sólo una "ilusión de la conciencia" en tanto el mundo nunca es un en-sí sino el resultado de un proyecto que le da sentido para el sujeto. [agradezco a Duque, Escobar y Franco (2006) por la ruta propuesta en su trabajo al pensamiento del filósofo colombiano Estanislao Zuleta).

7 Um corte epistemológico. Da educação física á motricidade humana (1999).

8 La ciencia de la motricidad humana es definida en el glosario inicial construido por Manuel Sergio (1999: 268) como: "ciencia de la comprensión y de la explicación de las conductas motoras, orientada al estudio y a las constantes tendencias de la motricidad humana en el orden del desarrollo global del individuo y de la sociedad, teniendo como fundamento simultáneo lo físico, lo biológico y lo antroposociológico".
Manuel Sergio (1999) en su tesis doctoral retomó a Tomas Khun ${ }^{9}$ para proponer un corte epistemológico entre la educación física y la motricidad humana, pero también conceptos como el de paradigma y de crisis paradigmática. Estos conceptos son, a mi juicio, generadores de dificultades que pueden convertirse en obstáculos insalvables. La propuesta de un corte epistemológico que significa pasar del paradigma cartesiano al paradigma de la complejidad, del empirismo cartesiano a la fenomenología y la hermenéutica, de la educación física a la ciencia de la motricidad humana, es problemática en tanto sugiere la irreconciabilidad entre ellos, ante la evidente crisis que el primero ha sufrido y que ha permitido la irrupción de un nuevo paradigma ${ }^{10}$. Una perspectiva que sugiere el paso del paradigma de la simplicidad al paradigma de la complejidad es dualista, aquello que precisamente, se denuncia en el primer paradigma, parece de nuevo ser la salida, dos formas de mirar la realidad que no son irreconciliables.

Por supuesto, esta irreconciabilidad ha generado, por lo menos en los contextos académicos donde me muevo (algunas regiones de Colombia), un rechazo del otro paradigma, de acuerdo al paradigma en el que uno se ubique. Así, los seguidores de la educación física y el deporte se niegan a la motricidad y los seguidores de la motricidad se niegan a la educación física y el deporte. La educación física en nuestro país sigue siendo no sólo la práctica instituida, sino también la práctica institucionalizada, considerada por el Ministerio de Educación Nacional como un área de formación fundamental a ser desarrollada en el espacio escolar, y los programas de formación de maestros en el área siguen teniendo, en términos generales, la denominación de Licenciatura en Educación Física ${ }^{11}$.

Manuel Sergio (1999: 23) planteó que la ciencia de la motricidad humana sin la educación física no tiene

\footnotetext{
9 Para ampliar, ver a Feitosa (1993).

${ }^{10}$ El paradigma es asumido por Thomas Kuhn (2000) [primera edición en inglés, 1962] como: "toda la constelación de creencias, valores y técnicas entre otras, que comparten los miembros de una comunidad (...) también denota una especie de elemento de tal constelación, las concretas soluciones de problemas que, empleadas como modelos o ejemplos, pueden remplazar reglas explícitas como base de la solución de los restantes problemas de la ciencia normal". Luego, este concepto fue remplazado por el mismo autor (1970) por el de "Matriz disciplinaria": disciplinar en tanto comparten una posición común y una disciplina particular; Matriz porque este conjunto se compone de elementos ordenados, de diversos tipos, exigiendo cada uno estudio detallado.

11 Existen varias denominaciones que aún no han podido ser unificadas, en parte por la apertura en los títulos otorgados por estos programas dependiendo del énfasis dado por los docentes en relación al objeto de estudio (sobre lo cual no existe consenso), o por el énfasis dado de acuerdo al nivel de la Educación Formal al cual va dirigido este último, provocado por el Decreto 272 de 1998 (Ministerio de Educación Nacional).
} 
historia, pero quienes defienden este paradigma por llamarlo en los mismos términos que Sergio lo hizo, se niegan a ser historia, asociando la historia con el pasado. Las prácticas de la Educación Física siguen estando presentes en la escuela, quizá se hayan transformado los discursos, pero a través de ella se sigue encarnando el deporte y todas sus significaciones imaginarias ${ }^{12}$. La postura de corte y de irreconciliabilidad no da espacio para la coexistencia, para la mixtura, para la hibridez que permita comprender, como todo buen historiador lo haría, la no desaparición total de los estratos históricos del pasado, pues estos siguen funcionando y continúan siendo fundantes en la construcción de las realidades sociales. Esta mixtura de significaciones imaginarias configura un universo simbólico híbrido, desde el cual los sujetos sociales legitiman sus realidades sociales (contextualizándolas históricamente), y a partir de éstos se producen procesos de subjetivación, como formas de ubicación y aprehensión en la vida social. Se trata de una sociabilidad híbrida ${ }^{13}$ espacialmente válida para América Latina, que pone en diálogo e interacción las significaciones, debido que las resignifica y las complejiza.

Una postura de mixtura, que no es eclecticismo ingenuo, puede significar superar el obstáculo que encuentran los programas de formación que han apostado a la motricidad como objeto de estudio o como núcleo fundante ${ }^{14}$. Significaría entonces, reconocer que la motricidad humana da elementos muy importantes para superar esa forma de mirar que visibiliza el cuerpo en binarias y que acentúa lo mecánico, lo anatómico, lo fisiológico y lo instrumental. Los esfuerzos por construir una reflexión que humanice el deporte y por configurar un nuevo juego de lenguaje como proceso poiético de una comunidad académica propositiva y creativa. Pero también, implica el reconocimiento de unos actores institucionales que desde la educación física y el deporte han resignificado sus prácticas en unos escenarios particulares, que hacen que esta clase siga siendo una línea de fuga para los estudiantes y un espacio de encuentro relacional distinto al aula ${ }^{15}$, así también aquellos esfuerzos por hacer del deporte un derecho humano, escenario de la participación, la prevención y la construcción de tejido social.

\footnotetext{
12 Para ampliar, en Hurtado et ál. (2005) y en Murcia et ál (2005).

13 El concepto de "sociabilidad hibrida" ha sido retomado del planteamiento de García Canclini (1990).

${ }^{14}$ Los dos casos a los que me refiero son los desarrollados en la Universidad del Cauca y en la Universidad de Antioquia.

15 Para ampliar, en Hurtado et ál (2005).
}

Esta posibilidad de asumir la mixtura, que va en la misma línea en la que se asume un nuevo juego de lenguaje, tiene la pretensión de crear nuevos encadenamientos de significantes, nuevas relaciones entre significantes y significados. Configurar desde esos intersticios, desde lo liminal, desde aquellos lugares que los discursos pre-existentes no alcanzaron (incluyendo la motricidad), esos espacios de libertad que el simbolismo no alcanzó a determinar.

La aceptación y legitimidad, o sea el proceso a través del cual se instituye este nuevo juego de lenguaje, no implica el rechazo a categorías pre-existentes, es sólo una nueva forma de mirar (en gris o en colores) y al mismo tiempo de problematizar aquello que está fuertemente instituido. Plantear, como lo propusiera Kolniyak (2005), una diferenciación entre lo motriz, lo motor y lo motríceo, y haber retomado la diferenciación entre cuerpo, corpóreo y corporeidad; no puede ser asumido como una oposición entre lo uno y lo otro que nos devolvería al dualismo, sino como una salida válida para expresar la mixtura de lo bio-antropo-cultural que se expresa en el cuerpo-sujeto cuando se mueve, o sea en el movimiento con sentido, en la motricidad. Las expresiones son motriceas si asumimos la perspectiva fenomenológica, pero también lo son cuando admitimos que el cuerpo "expresa", por tanto comunica; comunicación de un cuerpo en-el-mundo, de un "ser ahí" que es corpóreo. Lo que queda en discusión es si todo lo que éste expresa lo hace con sentido y si todo movimiento humano está cargado de intencionalidad.

Quizás Eugenia Trigo y cols. (1999) no previeron que al conceptualizar la motricidad humana como vivenciación de la corporeidad, se daría espacio a prácticas que desbordan el espacio escolar, la intencionalidad del currículo y las pretensiones adultocéntricas desde la cuales se pretenden direccionar estas vivencias en busca de superación, trascendencia ${ }^{16} \mathrm{o}$ desarrollo humano. Hoy día los jóvenes vivencian la corporeidad desde espacios y prácticas no institucionalizados ${ }^{17}$, donde viven precisamente al límite: límite entre el dolor y el no dolor, entre el miedo y el no miedo, entre el riesgo y el no riesgo, entre la muerte y la vida, entre lo posible y lo imposible. Quizás vivir al límite será el aprendizaje

16 La trascendencia es asumida en este texto como se desarrollará más adelante, como una expresión del dualismo que va en contravía de una propuesta que precisamente pretende superarlo.

17 Prácticas como las asociadas al riesgo y la aventura, como las denominamos para diferenciarlas de los deportes extremos, porque el acento no está colocado en lo agonístico, ni en la reglas sino por la vivencia de lo extremo, como vivenciación del límite (Jaramillo, Hurtado y Ocampo, 2004), (Mosquera, Simmonds y Hurtado, 2006). 
que hoy necesitamos, el ángulo de fuga que da lugar a la necesidad de aquello que excede lo circunscrito, a las posibilidades de ampliación de la racionalidad. El límite como potenciación y "como exigencia de apertura que, en consecuencia, contiene su misma transformación (...) el límite como lo conformado versus el límite como lo conformándose" (Zemelman, 1998: 31).

\section{Foucault y sus procedimientos de investigación}

Reseñaré, de manera sucinta, los procedimientos metodológicos, usados por Michel Foucault sin detenerme en ellos, pues ese no es mi propósito, la intención es mucho más modesta y es tratar de visibilizar cómo su aproximación a los objetos de saber que estudió, podrían darnos pistas para pensar ese campo complejo llamado motricidad humana.

Fueron tres los procedimientos que Foucault utilizó para adelantar sus trabajos: la arqueología, la genealogía y las tecnologías. Con el primer procedimiento, se ocupó del saber, el primer trabajo de éstos tres es La Historia de la locura que fue su tesis doctoral, posteriormente escribió Las palabras y las cosas y La arqueología del saber. A través del segundo procedimiento, su preocupación se centró en el poder y esta fue la manera como desarrolló el trabajo Vigilar y castigar. Con el último procedimiento que utilizó se ocupó del sí mismo, y le corresponden los tres tomos de la Historia de la sexualidad ${ }^{18}$.

Las preguntas que animaron los estudios de Foucault sobre la locura, el saber, el poder, la sexualidad, el sí mismo, no eran objetos de conocimiento, eran saberes que estaban por fuera de las disciplinas, de las instituciones (facultades, escuela, manicomio, auspicios, cárceles) y de unos actores privilegiados. Su trabajo fue una renuncia a pensar la escuela solamente desde la pedagogía, la locura desde la psiquiatría y desde el discurso médico, el poder desde el Derecho y el sí mismo desde la Psicología y el Psicoanálisis.

Foucault nos mostró cómo las apuestas de saber desbordan ampliamente las disciplinas y sus delimitaciones, esos dominios de coherencia e institucionalización elaborados a partir de modelos "científicos", donde los saberes se ordenan y se cultivan; las disciplinas se constituyen entonces en apuestas de conocimiento que no siempre permiten ver las condiciones de posibilidad, las

\footnotetext{
${ }^{18}$ Me refiero a La voluntad de saber (1984) [Primera edición en francés, 1976], El uso de los placeres, (1986) [primera edición en francés, 1984] y La inquietud de sí (1987) [primera edición en francés 1984].
}

coyunturas históricas y las contingencias que permitieron su institucionalización.

Pensar las Ciencias Sociales a partir de la obra de Foucault es renunciar a las preguntas por los limites disciplinares, por la pertinencia, por los cortes, por ese Régimen diurno que se impuso en Occidente y que nos obliga a discriminar, a disociar, a separar, "al estatismo y a la distinción de de la idea terminada y precisa, maniqueísmo originario del día y la noche, de la luz y la sombra", de lo bueno y lo malo. Es aquí donde el pensamiento de Foucault, a mi juicio, se cruza con los trabajos desarrollados por Durand (2004) sobre imaginarios, al hacerse evidente como el racionalismo occidental esta precedido por una imaginación diairética ${ }^{19}$ o sea una imaginación dual, de dos reinos, donde la divinidad esta en "otro lugar" y cuyo arquetipo central es la barrera que separa tinieblas de luz. Régimen de la espada, del acero de fuego, de la antorcha, agua y aire lustral; que se complace en lo abstracto, en lo inmóvil, en lo sólido, en lo rígido; de contornos tajantes que permiten la precisión de la forma, pero igualmente régimen de la trascendencia, que no es otra cosa que una expresión más de la filosofía del doble, donde "el espíritu es el doble del ser, como el mundo inteligible es el doble más autentico del mundo real" (Durand, 2004:188).

Renunciar a las empresas de la trascendencia que es el origen imaginario de los dualismos, es aceptar esa inclinación del pensamiento humano a negar lo existencial y lo temporal a través de caminos de ascensión, purificación y perfectibilidad. La trascendencia siempre tiene dos términos, por tanto separa y excluye. La modernidad se caracteriza por establecer una relación de exterioridad (interior/exterior); en esta perspectiva, la locura y la razón son dos cosas distintas, perspectiva de separación y exclusión que Foucault desmontó al demostrar que la locura fue creada por la no locura y comprobarlo arqueológicamente (Historia de la locura). La trascendencia excluye, si se piensa en la trascendencia del Derecho no se ve la inmanencia de la cárcel, si se piensa en la trascendencia de la Educación y la Pedagogía no se ve la inmanencia de la escuela, de la misma manera cuando se piensa en la trascendencia del ser humano, no se ve su ser corpóreo y sus múltiples formas de vivenciación.

\footnotetext{
${ }^{19}$ A los símbolos diairéticos a los que se refiere Gilbert Durand (2004) [primera edición en francés, 1992] corresponden las armas trascendentes para enfrentar a los contrarios (el mal, las tinieblas, Satán, el ogro) como son la espada, la flecha, el rayo, el hacha entre otros.
} 


\section{Las máquinas ópticas y los imaginarios}

Es necesario aclarar que Foucault no desarrolló trabajos sobre imaginarios sociales, sin embargo una de sus grandes preocupaciones fue la relativa a la visibilidad y es aquí donde me parece interesante plantear las cercanías que encuentro con el planteamiento de Juan Luis Pintos sobre imaginarios sociales.

Para Juan Luis Pintos (2000), los imaginarios sociales son "aquellos esquemas construidos socialmente que nos permiten percibir, explicar e intervenir en lo que cada sistema social se considere como realidad". La realidad se construye socialmente mediante diferentes dispositivos en pugna entre Estado, mercado y empresas de construcción de realidad; a éstas se suman otras instituciones como la religiosa y educativa que también matizan esas realidades. Los imaginarios entonces permitirán a juicio de Pintos, una suerte de relevancia/opacidad de la realidad de acuerdo con los programas teóricos que los sustentan, a los cuales denomina de tipo exclusivo y de tipo inclusivo. Dentro de los programas teóricos exclusivos se encuentran el teológico y el filosófico ilustrado, a los cuales les corresponde una realidad única y la entrega divina o la búsqueda de una sola verdad; dentro de los programas de tipo inclusivo ubica el programa sociológico crítico y el constructivismo sistémico, a los cuales les corresponde más de una realidad y, al mismo tiempo, el reconocimiento de múltiples verdades.

Entonces, las relevancias y sus correspondientes significaciones imaginarias son el lado visible de la realidad y al mismo tiempo sus condiciones de posibilidad, de ahí que el discurso, a juicio de Foucault, no pueda liberarse de la historia de los juegos de verdad que han sido instituidos, de los regimenes discursivos que establecen lo que es verdadero y lo que es falso. El paralelismo que se puede establecer entre lo que se ve y lo que se oculta, lo que dice y lo que se calla. El régimen diurno de la imagen ha sido el crisol para construir el conocimiento en Occidente, que es igualmente el régimen de la dicotomía y de la trascendencia, el régimen de las disciplinas como lado visible de la distinción que construye la verdad, la instituye y la legítima.

El problema de la visibilidad en Foucault es formulado por Larrosa (1995: 296-300) a través del concepto de máquinas ópticas, o sea como aquel mecanismo que integra en un sólo movimiento lo que es visible y el ojo que ve, el sujeto y el objeto de la mirada. El conocimiento como apuesta de ordenamiento de lo verdadero ha tenido más relevancia que la perspectiva de saber, y es im- portante resaltar esa diferenciación entre conocimiento y saber de forma simple, por muy amplio que pretenda ser este ordenamiento (conocimiento), por muy abierto y flexible, siempre lo que queda por fuera será mayor (saber/saberes), aquí podríamos utilizar el símil del encuadre cinematográfico; ubiquemos, entonces, un paisaje con gran amplitud y gran profundidad, sin embargo lo que queda por fuera del encuadre será superior.

La ruta investigativa como apuesta de saber me recuerda el reclamo de los estudiantes una vez se enfrentan a la práctica escolar o una vez egresan ${ }^{20}$ acerca de la pertinencia de los contenidos desarrollados (currículoconocimiento); la realidad de la escuela es mucho más grande que los contenidos de las diferentes unidades temáticas, de ahí que la práctica profesional los avasalle, los arrase; preguntándose por qué esto y estas otras cosas no me las enseñaron, porque se les olvidaran las dinámicas de poder, la marginalidad de la educación y del maestro en nuestro país, la marginalidad de la educación física en el currículo escolar, las exclusiones, las dificultades económicas de maestros y estudiantes. Un descubrirse, un abrirse a un mundo vivido que habían olvidado, por lo tanto ajeno; una realidad vivida como estudiantes, como niños, niñas y jóvenes que se aleja de esa elaboración que la disciplina entre esas la pedagogía y la psicología han elaborado. No son los niños y las niñas de la moratoria social que la escuela visibilizó, ni los locos y locas "adoleseres" en crisis, se trata de seres que desbordan ampliamente la pedagogización y la psicologización de la que son victimas. Son actores sociales con significaciones imaginarias construidas en múltiples espacios de socialización, en la negociación constante con sus situaciones de vida y muerte, que van desde la abundancia hasta la escasez, desde el consumo hasta la exclusión.

Una crítica que podríamos plantear a Foucault y a su planteamiento sobre esa autonomía del discurso, esas condiciones de posibilidad que determinan la verdad desde la historia y los sujetos que se producen en su interior, es que ésta sería válida sólo para aquello que nos es instituido. Queda por fuera la posibilidad de lo instituyente, la posibilidad de creación que rompe con el pensamiento de la determinación y que se ubica en los territorios de lo sombrío, lo opaco, lo emocional, lo pasional y lo afectivo, de lo ajeno al plan y al método. Régimen nocturno y dionisiaco por excelencia donde la ambigüedad, la incertidumbre y la indeterminación son las distinciones. No se trata de oponer el régimen diurno

\footnotetext{
20 Me refiero a los estudiantes del Programa de Licenciatura en Educación Básica con Énfasis en Educación Física, Recreación y Deportes de la Universidad del Cauca.
} 
con el nocturno de manera dicotómica, sino de visibilizar a partir de una forma distinta de mirar, bebiendo de las dos aguas para que ese régimen de la espada no nos corte y nos fragmente, y para que el régimen nocturno, vaginal y acuático, no nos trague.

Los imaginarios podrían ser pensados como una máquina óptica de relevancias y opacidades, máquina de la inmanencia si se quiere, que se libera de la trascendencia y la determinación, y que es abierta a la creación, "fuente de lo que se da cada vez como sentido de la realidad, soporte de las articulaciones de lo que importa y de lo que no importa" (Beriain, 2005: 156). Pero al mismo tiempo fuente de creación de significaciones que instituyen unas nuevas relevancias: "En la historia, desde el origen constatamos la emergencia de lo nuevo radical, y si no podemos recurrir a factores trascendentes para dar cuenta de eso, tenemos que postular necesariamente un poder de creación, un vis formandi, inmanente tanto a las colectividades humanas como a los seres humanos singulares" (Castoriadis, 2002: 94) 21. $^{21}$

Para mí la motricidad humana no es una ciencia, ni una disciplina, es un campo de lucha, un campo ${ }^{22}$ emer-

21 Primera edición en francés (1999) [póstuma].

22 Asumo el concepto de campo desde los planteamientos de Bourdieu para quien éste se define "como una red o configuración de relaciones objetivas entre posiciones. Estas posiciones se definen objetivamente en su existencia y en las determinaciones que imponen a sus ocupantes, ya sean agentes o instituciones, por su situación (situs) actual y potencial en la estructura de la distribución de las diferentes especies de poder (o de capital)" (1995, p. 61). Se resalta en este concepto su carácter relacional y se acentúa el rechazo por todo tipo de oposición entre el análisis objetivista y subjetivista, o de separación entre el estudio del individuo y de la sociedad, para lo cual el concepto de configuración desarrollado por Norbert Elias (1996) [Primera edición en alemán, 1969] puede ser muy iluminador.

\section{4}

\section{Referencias}

Bauman, Z. (2005). Amor líquido. Acerca de la fragilidad de los vínculos humanos. Buenos Aires: Fondo de Cultura Económica.

Beriain, J. (2005). Modernidades en disputa. Barcelona: Anthropos.

Bourdieu, P. (1995). Respuestas. México: Grijalbo.

Castoriadis, C. (2002). Figuras de lo pensable (Las encrucijadas del laberinto VI). México: Fondo de Cultura Económica.

Duque, Escobar y Franco. (2006). La motricidad humana según Manuel Sergio y Merleau-Ponty. Documento universitario. Maestría en Educación y Desarrollo Humano. Universidad de Antioquia.

Durand. G. (2005). Las estructuras antropológicas del imaginario. México: Fondo de Cultura Económica.

Elias, N. (1996). La sociedad cortesana. México: Fondo de Cultura Económica.

Feitosa, A. (1993). Contribuições de Thomas Kuhn para una epistemología da motricidad humana. Lisboa: Instituto Piaget. gente, una forma de mirar que a pesar de su amplitud y complejidad no deja de adoptar un régimen imaginario distinto (en mixtura y liminal) que nos pone sobre las sendas de saberes que desbordan los límites de las disciplinas y visibilizan nuevas rutas, algunas de ellas insospechadas para quienes están dispuestos a emprenderlas. Un campo problemático que configura un entramado denso, con múltiples entradas, opaco, con inmensa cantidad de elementos nuevos y confusos académicamente debido a la urdimbre que en él se entretejen.

Los saberes del cuerpo, las diversas formas de vivenciación de la corporeidad no podrán ser abarcadas en su totalidad por ninguna forma de organización del conocimiento llámese motricidad, educación física, fisiología, morfología, antropología, entre otras. En el cuerpo existe un amplio espacio para la emoción, el placer y el deseo, para lo inefable y dionisiaco que ninguna lógica categorial puede abarcar, así "todo intento de estructuración abarcadora deja numerosos 'cabos sueltos' e implicaciones polémicas, produce puntos ciegos, zonas indefinidas, ambigüedades y tierras de nadie inexploradas y sin cartografía oficial" (Bauman, 2005: 101). Espacios donde las sobras del esfuerzo ordenador, dan paso a la imaginación creadora que rompe y abre espacio hacia caminos inexplorados, hacia brechas e incertidumbres, caminos donde lo radical se inscribe en la espontaneidad, la experimentación, la vivencia y la autodeterminación.
Foucault, M. (1984). La historia de la sexualidad: La voluntad del saber. Iztapalapa: Siglo XXI Editores.

Foucault, M. (1986). La historia de la sexualidad 2. El uso de los placeres. México: Siglo XXI Editores.

Foucault, M. (1987). La historia de la sexualidad 3. La inquietud de sí. México: Siglo XXI Editores.

Foucault, M. (1984). Vigilar y castigar. México: Siglo XXI Editores.

García Canclini, N. (1990). Culturas híbridas. Estrategias para entrar y salir de la modernidad. México: Grijalbo.

García. M. (2005). La dualidad. Una cierta incomodidad. En Trigo, Hurtado y Jaramillo (Comp.). Con-sentido. Popayán: Universidad del Cauca.

Heidegger, M. (2004). El ser y el tiempo. México: Fondo de Cultura Económica. 
Hurtado, Jaramillo, Zúñiga y Montoya. (2005). Jóvenes e imaginarios de la Educación Física. Un estudio comprensivo con jóvenes escolarizados en la ciudad de Popayán. Popayán: Universidad del Cauca.

Hurtado, Jaramillo y Ocampo. (2004). Deporte Extremo Como Práctica Social y posibilidad de adscripción identitaria en jóvenes urbanos. Revista digital Lecturas: Educación Física y Deportes, 10,73 .

Kolyniak, K. (2005). "Propuesta de un glosario inicial para la ciencia de la Motricidad Humana". En: Trigo, Hurtado y Jaramillo (comp.). Con-sentido. Popayán: Universidad del Cauca, pp. 29-37.

Kuhn, T. (2000). La estructura de las revoluciones cientificas. México: Fondo de Cultura Económica.

Larrosa. J. (1995). Tecnologías del Yo y educación. Notas sobre la construcción y la mediación pedagógica de la experiencia de sí. En J. Larrosa (comp.). Escuela, poder y subjetivación. Madrid: La Piqueta.

Pintos. J. L. (2000). Construyendo realidad(es): Los imaginarios sociales. Santiago de Compostela. Disponible en http//web.usc.es.

McLaren, P. (1997). Pedagogía crítica y cultura depredadora. Políticas de oposición en la era posmoderna. Barcelona: Paidós.

Mèlich, J. C. (1994). Del extraño al cómplice. La educación en la vida cotidiana. Barcelona: Anthropos.
Merleau-Ponty, M. (2000). Fenomenología de la percepción. Barcelona: Peninsula.

Morin, E. (2001). Los siete saberes necesarios para la educación del futuro. Bogotá: Cooperativa Editorial Magisterio.

Mosquera, Simmonds y Hurtado. (2006). El skate boarding: la corporeidad puesta al límite. Documento universitario. Universidad del Cauca.

Murcia, Jaramillo, Camacho y Loaiza. (2005). Los imaginarios de los jóvenes ante la clase de educación física. Informe final. Armenia: Colciencias-Kinesis.

Rodríguez, M. (1997). Identidades: El profesor de educación física en los escenarios de la posmodernidad. Lecturas: Educación Física y Deportes, 2,4 .

Savater, F. (1996). El valor de educar. Madrid: Ariel.

Sergio, M. (1999). Um corte epistemológico. Da educação física á motricidade humana. Lisboa: Instituto Piaget.

Trigo, E. y Cols. (1999). Creatividad y motricidad. Barcelona: Inde,

Zemelman, H. (1998). Sujeto, existencia y potencia. Barcelona: Anthropos,

Zuleta, E. (1980). El pensamiento psicoanalítico. Medellín: Hombre Nuevo. 